\title{
Multi-touch Gestures Authentication Techniques: A Study
}

\author{
Mr. Ramdas Pandurang Bagawade ${ }^{1}$, Ms. Bhagyashri Satish Bagal ${ }^{2}$, Ms. Monika Kishor Kale ${ }^{3}$, \\ Ms. Trupti Chandrakant Jangam ${ }^{4}$ \\ Asst. Prof, Computer Engineering, PES's College of Engineering, Phaltan, India ${ }^{1}$ \\ B.E. Scholar, Computer Engineering, PES's College of Engineering, Phaltan, India ${ }^{2,3,4}$
}

\begin{abstract}
In current era the multitouch interfaces interactions with computing devices are changing fastly. The common problems related to users for user authentication are selecting weak textual passwords or forgetting password [1]. Hence we studied gesture based multitouch authentication system. Multitouch gestures based on the movement characteristics of the palmand fingertips being used to perform the gesture[1]. We studied a various techniques to verify multi-touch gesture templates. With score-based classifiers where only the first five samples of a good subject were considered as templates, author achieved4.46 \% EER [1]. Further, with the combination of three commonly used gestures like pinch, zoom, and rotate, using more than one finger, $1.58 \%$ EER was achieved[1].Touch and multi-touch gestures are the most common way to interact with technology such as smart phones, tablets and other mobile devices[1].
\end{abstract}

Keywords: Finger-tracking, Android Operating system, Eclipse, Gesture, Normalization.

\section{INTRODUCTION}

Currently the smart phone users growing day by day. There are various applications that requires strong authentication. Single touch technology i.e. previously used technology also provides user authentication. In this system multitouch interface bring new capabilities to existing devices. In the smart phones, tablets, in living room, coffee table the multitouch technology is used. It is an effective user interaction features and the visual Experience provided by multi-touch interfaces, make them strong contenders for becoming the dominant human computer interface, possibly replacing the keyboard, mouse and stylus. Proof of identity of user is an input to multi-touch gesture authentication system. Correctness of the proof of identity is then evaluated by the system. After that, the answer, either accepts or rejects the user, is given based on the evaluation result. Enrollment stage and verification stage are two phases in verification system. In the enrolment stage the user's input is stored in the system. During verification stage, the user input is compared with the already stored biometric templates of the respective user while performing authentication [1]. There are various phases used in verification phases.

Multi-touch gesture based authentication consist the stages such as developing a gesture authentication technique, Matching touch sequences to specific fingers, Fingertracking, Gesture Normalization, Feature Extraction, Distance evaluation, Thresholding[1].

\section{GESTURE NORMALIZATION}

Normalization is a transformation process that scales down data value within a feature. Large difference between the minimum and maximum value of a feature need to bring this variation to some acceptable range[1]. 0 and 1 are the specified range data values. Classification algorithms are used for this process along with min-max normalization. There are various techniques used in normalizations.

\section{A. Intriguing technique}

Retention of the correlation between actual dataset and accomplishing linear transformation on them are the key points in this technique. A feature value $\mathrm{V}$ is mapped to $\mathrm{V}^{\prime}$ in min-maxnormalization, using the Equation (1).

$$
V^{\prime}=\frac{\mathrm{V}-\min }{\max -\min }(1)
$$

Significant information loss and concentration of values on certain parts of the normalized range occurs because of min-max normalization.

\section{B. Block Scaling Normalization}

Shifting the coordinates using centre mass is present techniques for normalization so that the centroid of the object will match. We need to perform rescale between new presented object and the stored objects so that match will occur. To enhance system performance cleaning up of data is necessary in the normalization phase.

\section{FEATURE EXTRACTION}

Feature extraction is responsible for generating the user template, by identifying and encoding distinguishing properties from a user's biometric data. Templates from two different users must be distinct and different and templates that are from the same user should be identical. 
In this research workthis process is very fundamental. Next phase is classification is nothing but it converts the biometric data into a feature vector to use as an input in the next phase[1]. To extract features that are discriminating with respect to the way users interact with a touch screen behavior this is purpose of extraction[2].

The collected raw data is main task of touch gesture application. In an android platform called Motion Event used todata collected in this research were from features that extracted using the application-programming interface, This API makes it possible to gather touch screen data for a touch event differs from other operating systems.

A human finger touch; finger pressure down, finger pressure up, finger size down, finger size up, duration, acceleration, distance, speed, touch major down, touch major down up, touch minor down, touch minor up and position this are thirteen features that extracted from.

The extracted features shown in Figure A. Figure shows touch features used in this research. With the TouchEvent () method in Android, a set of touch features can collected from the screen during the different types of touch event [3].

Table 1 shows the different way of extracting the features form human touch. There are consider distance, time, acceleration, position, speed etc factors when the user touches the screen to user release his finger from screen. According to their feature there are various types of features methods are used show in Table 1.

Tables 2 and 3 summarize the most interesting verification systems presented online and offline. In Tables 2 and 3 systems has EER, FAR, FRR factors shown in results of a systems. In multitouch gesture verification produce two types of errors false rejection rate (FRR) and false acceptance rate (FAR) by helping of this factor performance of system is measure. The error factors FAR and FRR are vice versa depending upon systems. The equal error rate calculated by the overall error of systems [3].

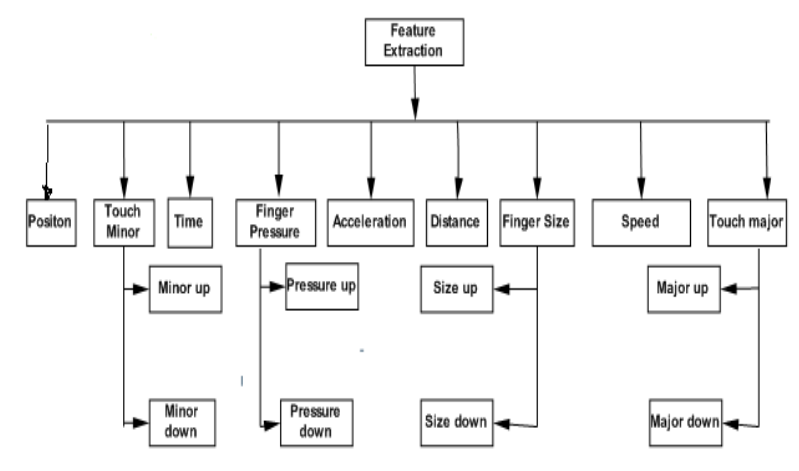

Figure 1.Feature extraction and feature component [3]
TABLE 1: FEATURES TABLE [3]

\begin{tabular}{|c|c|c|}
\hline No & Features & Methods \\
\hline 1 & $\begin{array}{l}\text { Finger } \\
\text { Pressure } \\
\text { Down, Finger } \\
\text { Pressure Up }\end{array}$ & $\begin{array}{l}\text { To extract finger pressure } \\
\text { value we used android } \\
\text { library getPressure () method } \\
\text { measured by kilopascals. }\end{array}$ \\
\hline 2 & $\begin{array}{l}\text { Finger Size } \\
\text { Down, } \\
\text { Finger Size Up }\end{array}$ & $\begin{array}{l}\text { To extract finger size value } \\
\text { we used android library } \\
\text { getSize () method measured } \\
\text { by pixels. }\end{array}$ \\
\hline 3 & Time (ms) & $\begin{array}{l}\text { The event press time along } \\
\text { with the event release time } \\
\text { were extracted from the two } \\
\text { methods getDownTime }() \\
\text { and getEventTime () } \\
\text { respectively. }\end{array}$ \\
\hline 4 & Acceleration & $\begin{array}{l}\text { The formula (Speed /Time) } \\
\text { was used to calculate } \\
\text { acceleration. }\end{array}$ \\
\hline 5 & Distance & $\sqrt{(\mathrm{x} 2-\mathrm{x} 1)^{2}+(\mathrm{y} 2-\mathrm{y} 1)^{2}}$ \\
\hline 6 & Speed & $\begin{array}{l}\text { The formula } \\
\text { (Distance/Time) was used } \\
\text { compute speed. }\end{array}$ \\
\hline 7 & $\begin{array}{l}\text { Touch Major } \\
\text { Down, } \\
\text { Touch Major } \\
\text { Up }\end{array}$ & $\begin{array}{l}\text { To extract the length of the } \\
\text { Touch Major axis the } \\
\text { android library method } \\
\text { getTouchMajor } \\
\text { (intpointerIndex) was used. }\end{array}$ \\
\hline 8 & $\begin{array}{l}\text { Touch Minor } \\
\text { Down, } \\
\text { Touch Minor } \\
\text { Up }\end{array}$ & $\begin{array}{l}\text { To extract the length of the } \\
\text { Touch Minor axis the } \\
\text { android library method } \\
\text { getTouchMinor } \\
\text { (intpointerIndex) was used. }\end{array}$ \\
\hline 9 & Position & $\begin{array}{l}\text { Position is reading the } \\
\text { coordinates value of } x \text {-axis } \\
\text { and } y \text {-axis of touch point } \\
\text { location through GetX }() \text {, } \\
\text { GetY (). }\end{array}$ \\
\hline
\end{tabular}

TABLE 2: PERFORMANCES: ONLINE SYSTEMS [3]

\begin{tabular}{|c|c|c|}
\hline Main Features & Approach & Results \\
\hline $\begin{array}{c}\text { X-Y correlation, } \\
\text { projection- based, } \\
\text { Moment-based }\end{array}$ & NN & FRR:3\% \\
\hline $\begin{array}{c}\text { Projection based, } \\
\text { Contour based. }\end{array}$ & NN & FRR:1\%, \\
\hline $\begin{array}{c}\text { Geometric-based, } \\
\text { Projection-based, } \\
\text { slant-based, grid- } \\
\text { based }\end{array}$ & NN(RBF) & FRR:3\%, \\
\hline $\begin{array}{c}\text { Contour-based } \\
\text { FAR:9.81\% }\end{array}$ & $\begin{array}{c}\text { NN(MLP) (ME } \\
\text { by cascaded } \\
\text { Multiple experts }\end{array}$ & FRR:2.04\%, \\
\hline Wavelet transform & DTW & FRR:5.601\% \\
& & FAR:10.98 \\
\hline
\end{tabular}




\begin{tabular}{|c|c|c|}
\hline & & $\%$ \\
\hline $\begin{array}{l}\text { Geometric-based, } \\
\text { Projection-based, } \\
\text { slant-based, } \\
\text { Fourier Transform }\end{array}$ & $\begin{array}{c}\text { Euclidean } \\
\text { Distance, NN }\end{array}$ & $\begin{array}{l}\text { FRR:2\%, } \\
\text { FAR:0.5\% }\end{array}$ \\
\hline Grid-based & HMM & $\begin{array}{l}\text { FRR:0.75\%, } \\
\text { FAR:0.18\% }\end{array}$ \\
\hline $\begin{array}{l}\text { Global(Wavelet- } \\
\text { based), statically } \\
\text { and geometrical }\end{array}$ & NN & $\begin{array}{l}\text { FRR:6.2, } \\
\text { FAR:5.5\% }\end{array}$ \\
\hline Projection-based & DTW & $\begin{array}{l}\text { FRR:22.\%, } \\
\text { FAR:23.5\% }\end{array}$ \\
\hline Peripheral-based & $\begin{array}{c}\text { Mahalanobis } \\
\text { distance }\end{array}$ & EER:11.4\% \\
\hline Geometric-based & $\begin{array}{l}\text { 1.Euclidean } \\
\text { Distance } \\
\text { 2.SVM } \\
\text { 3.HMM }\end{array}$ & $\begin{array}{c}\text { 1.FRR:5.61, } \\
\text { FAR:4.96\% } \\
\text { 2.FRR:3.23 } \\
\%, \\
\text { FAR:2.65\% } \\
\text { 3.FRR:2.2\% } \\
\text { FAR:3.3\% }\end{array}$ \\
\hline $\begin{array}{c}\text { Geometric-based, } \\
\text { grid-based }\end{array}$ & $\mathrm{NN}$ & $\begin{array}{l}\text { FRR:11.1\%, } \\
\text { FAR:11.8\% }\end{array}$ \\
\hline $\begin{array}{l}\text { Geometric-based, } \\
\text { Direction-based }\end{array}$ & $\mathrm{NN}$ & $\begin{array}{l}\text { FRR:6.3\%, } \\
\text { FAR:8.2\% }\end{array}$ \\
\hline $\begin{array}{l}\text { Graph metric- } \\
\text { based }\end{array}$ & HMM & $\begin{array}{l}\text { FRR:0.75\%, } \\
\text { FAR:0.22\% }\end{array}$ \\
\hline Grid-based & $\begin{array}{l}\text { Fuzzy logic } \\
\text { modeling }\end{array}$ & $\begin{array}{l}\text { FRR:0\%, } \\
\text { FAR:3.5\% }\end{array}$ \\
\hline Position & $\begin{array}{c}\text { Displacement } \\
\text { Function }\end{array}$ & EER:24.9\% \\
\hline Gird-based & $\mathrm{NN}$ & $\begin{array}{l}\text { FRR:7.27, } \\
\text { FAR:11\% }\end{array}$ \\
\hline
\end{tabular}

TABLE 3: PERFORMANCES: ONLINE SYSTEMS [3]

\begin{tabular}{|l|l|l|}
\hline Main Features & Approach & Results \\
\hline $\begin{array}{l}\text { Position, } \\
\text { Velocity, } \\
\text { Acceleration }\end{array}$ & DTW & EER:0.4\% \\
\hline $\begin{array}{l}\text { Shaped-based } \\
\text { features }\end{array}$ & DTW & $\begin{array}{l}\text { FRR:3.2\%, } \\
\text { FAR:0.55\% }\end{array}$ \\
\hline $\begin{array}{l}\text { Velocity, } \\
\text { Pressure }\end{array}$ & DTW & EER:4\% \\
\hline $\begin{array}{l}\text { Velocity, } \\
\text { Curvature based }\end{array}$ & String matching & $\begin{array}{l}\text { FAR:3.3\%, } \\
\text { FAR:2.7\% }\end{array}$ \\
\hline X-Y correlation & HMM & EER:2.5\% \\
\hline Geometric-based & $\begin{array}{l}\text { Mahalanobis } \\
\text { distance, } \\
\text { Euclidean } \\
\text { Distance, DTW }\end{array}$ & $\begin{array}{l}\text { FRR: 5.8\%, } \\
\text { FAR: } 0 \%\end{array}$ \\
\hline
\end{tabular}

System's performance can be measured by using factors such as EER, FAR, FRR.

Equal error rate (EER) is an algorithm in biometric In Cartesian coordinates, the length of the line that security system which is used to determine the threshold connects point's $\mathbf{p}$ and $\mathbf{q}$ is Euclidean distance between values for false rejection rate andfalse acceptance rate. If these points. the rates are equal, then common value is called as the equal error rate[4].

The false acceptance rate, or FAR, in biometric security system the rate at which the system wrongly accept an access attempt by an illegitimate user. A system's FAR is defined as the rate of the number of false acceptances divided by the number of identification attempts [4].

The false rejection rate the biometric security system will wrongly reject an access attempt by legitimate user. A system's FRR typically is defined as the rate of the number of false rejections divided by the number of identification attempts[4].

$$
\begin{gathered}
\mathbf{F A R}=\frac{\text { Wrongly accepted individuals }}{\text { Total number of wrong matching }} \\
\mathbf{F R R}=\frac{\text { Wrongly rejected individuals }}{\text { Total number of correct matching }}
\end{gathered}
$$

\section{DISTANCE EVALUATION}

On multitouch devices the number of touch point occurred and points differs from one multi-touch gesture to another if they were performed by the same user. The distance between two multi-touch gestures is calculated using dynamic time warping (DTW) algorithm [1]. To measure similarity between two time series that may have different lengths and time deformations by using DTW are a wellknown matching algorithm. Given two time series, the DTW algorithm does a rule-wise linear mapping of the time axes to align the two sequences while minimizing overall warping cost. The formula is as follows [2]

Let $\pi=\left\langle\mathrm{p}_{1}, \mathrm{p}_{2}, \ldots, \mathrm{p}_{\mathrm{n}}>\right.$ and $\sigma=\left\langle\mathrm{q}_{1}, \mathrm{q}_{2}, \ldots, \mathrm{q}_{\mathrm{n}}\right\rangle$

Is the sequence of feature points derived from two gestures $\pi$ and $\sigma$. Let $M=\left\{\left(p_{i} q_{i}\right)\right\}$ be an order-preserving complete correspondence between $\pi$ and $\sigma$, and cost (p, q) a matching cost between $\mathrm{p}$ and $\mathrm{q}$. The distance between $\pi$ and $\sigma$ is defined as

$$
\text { Distance }(\pi, \sigma)=\frac{\min \sum_{\forall(p, q) \in M} \operatorname{cost}(\mathrm{p}, \mathrm{q})}{\min ((\mathrm{m}, \mathrm{n})}[2]
$$

There is following ways are used to calculate the distance between touch points.

A. Manhattan distance

The Manhattan distance is calculated by adding difference of two points.

$$
\text { CostManhattan (p, q) }=\sum_{i=1}^{l}\left|p_{i}-q_{i}\right| \text { [1] [2] [6] }
$$

The formula for this distance between a point $P=\left(p_{1}, p_{2}\right.$ etc.) and a point $q=\left(q_{1}, q_{2}\right.$, etc.) isthe number of variables are denoted by $\mathrm{n}$, and the values of the $\mathrm{i}^{\text {th }}$ variable for $\mathrm{p}$ and $q$ are denoted by $p_{i}$ andq $q_{i}$.

B. Euclidean distance 
Suppose there are two pointsp $=\left(\mathrm{p}_{1}, \mathrm{p}_{2} \ldots \mathrm{p}_{\mathrm{n}}\right)$ and threshold values for false rejection rate and false $\mathbf{q}=\left(\mathrm{q}_{1}, \mathrm{q}_{2} \ldots \mathrm{q}_{\mathrm{n}}\right)$ in Euclidean formula, then the distance $(\mathrm{d})$ acceptance rate. If the rates are equal, then common value is calculated between $\mathbf{p}$ to $\mathbf{q}$, or $\mathbf{q}$ to pis bythe formula is called as the equal error rate [4].

Cost Euclidean $(p, q)=\sqrt{\sum_{i=1}^{l}\left(p_{i}-q_{i}\right)^{2}} \quad$ [1] [2] [6]

Euclidean vector defines the position of a point in a Euclidean formula. So, here $\mathrm{p}$ and $\mathbf{q}$ are considered. As Euclidean vectors, they start from the origin.

\section{Cosine distance}

$$
\text { CostCosine }(p, q)=1-\frac{p . q}{\|p\| \mid\|q\|}[1][2][6]
$$

Euclidean dot product formula is used to derive the cosine of two non zerovectors.

$$
a \cdot b=\|a\|\|b\| \cos \theta
$$

Dot productandmagnitudeare used to representtwo vectors that are nothing but $\mathrm{A}, \mathrm{B}$ and $\cos (\theta)[2]$. The result is defined in the form of -1 means opposite to similarity and 1 means same, where 0 shows in-between valuesintermediate similarity or dissimilarity. While performing text matching, the $\mathrm{A}$ and $\mathrm{B}$ are attribute vectors called frequency vectors of the documents. The cosine similarity is defined during comparison method by normalizing document length.

\section{Jaccard Index distance}

The Jaccardindex is termed as the Jaccard similarity coefficient. Originally it is developedby Paul Jaccard.

It is used for statisticand comparing the similarity and diversity between sample sets. It is termed as the intersection size divided by the union size between the sample sets.

$$
J(X, Y)=1-\frac{|X \cap Y|}{|X|+|Y|-|X \cap Y|}[1]
$$

Where $\mathrm{X}$ and $\mathrm{Y}$ are two samples sets. 0 to 1 is the range that used to define cosine similarity of two documents in case of information retrieval; hence negative frequencies are not acceptable. The value of the angle should not more than 90. Centred cosine similarity it means the attribute vectors are normalized by subtracting the vector that is the measureand is same to the Pearson Correlation Coefficient. Lastly, a dissimilarity score is computed from all pairwise distances between an input test gesture and the enrolled samples corresponding to an identity as follows,

$$
\text { Score }(\pi, \sigma)=\sum_{\mathrm{i}=1}^{\mathrm{N}}\left(\frac{\text { distance }(\pi, \sigma \mathrm{i})}{\sum_{\mathrm{j}=1}^{\mathrm{N}} \text { distance }(\sigma \mathrm{j}, \sigma \mathrm{i})}\right)[2]
$$

Wherei $=1 \ldots \mathrm{N}, \sigma=\{\sigma \mathrm{i}\}, \pi=$ test gesture,

And $\sigma=$ enrolled gesture

If score $(\pi, \sigma)$ is less than a predefined threshold then system accepts a test gesture $\pi$ otherwise it rejects. FAR or False Acceptance Rate means the system wrongly accepts an impersonation gesture or a biometric. FRR or False Rejection Rate is the rate at which the system wrongly

\begin{tabular}{|c|c|c|c|}
\hline $\begin{array}{l}\text { Annotat } \\
\text { ion }\end{array}$ & $\begin{array}{l}\text { Palm } \\
\text { Movemen } \\
\text { t }\end{array}$ & $\begin{array}{l}\text { Fingertip } \\
\text { movement }\end{array}$ & $\begin{array}{l}\text { Dynamic } \\
\text { Fingertip }\end{array}$ \\
\hline $\begin{array}{l}\text { 'CCW' } \\
\text { 'CW' } \\
\text { 'Pinch' } \\
\text { 'Drag' } \\
\text { 'DDC' }\end{array}$ & $\begin{array}{l}\text { Static } \\
\text { Static } \\
\text { Static } \\
\text { Dynamic } \\
(\downarrow) \\
\text { Dynamic } \\
(\searrow)\end{array}$ & $\begin{array}{l}\text { Circular } \\
\text { (CCW) } \\
\text { Circular } \\
\text { (CCW) } \\
\text { Close } \\
\text { Parallel } \\
\text { Close }\end{array}$ & $\begin{array}{l}\text { All } \\
\text { All } \\
\text { All } \\
\text { All } \\
\text { All }\end{array}$ \\
\hline $\begin{array}{l}\text { 'DUO' } \\
\text { 'FDB' } \\
\text { 'FBSB' } \\
\text { 'FASB' } \\
\text { 'FPCC } \\
\text { W' }\end{array}$ & $\begin{array}{l}\text { Dynamic } \\
(\nwarrow) \\
\text { Static } \\
\text { Static } \\
\text { Static } \\
\text { Static }\end{array}$ & $\begin{array}{l}\text { Open } \\
\text { Parallel( } \downarrow \text { ) } \\
\text { Parallel } \\
\text { (shape) } \\
\text { Parallel } \\
\text { (shape) } \\
\text { Circular } \\
(\mathrm{CCW})\end{array}$ & $\begin{array}{l}\text { All } \\
\text { Fixed thumb } \\
\text { and pinky } \\
\text { Fixed thumb } \\
\text { and pinky } \\
\text { Fixed thumb } \\
\text { and pinky } \\
\text { Fixed pinky }\end{array}$ \\
\hline $\begin{array}{l}\text { 'FPC' } \\
\text { 'FPO' } \\
\text { 'FPP' } \\
\text { 'FTCC } \\
\text { W' } \\
\text { 'FTCW' }\end{array}$ & $\begin{array}{l}\text { Static } \\
\text { Static } \\
\text { Static } \\
\text { Static } \\
\text { Static }\end{array}$ & $\begin{array}{l}\text { Close } \\
\text { Open } \\
\text { Parallel }(\downarrow) \\
\text { Circular } \\
\text { (CCW) } \\
\text { Circular(CW) }\end{array}$ & $\begin{array}{l}\text { Fixed pinky } \\
\text { Fixed pinky } \\
\text { Fixed pinky } \\
\text { Fixed thumb } \\
\text { Fixed thumb }\end{array}$ \\
\hline $\begin{array}{l}\text { 'FTC' } \\
\text { 'FTO' } \\
\text { 'FTP' } \\
\text { 'Flick' } \\
\text { 'Opened }\end{array}$ & $\begin{array}{l}\text { Static } \\
\text { Static } \\
\text { Static } \\
\text { Dynamic } \\
(\searrow) \\
\text { Static } \\
\end{array}$ & $\begin{array}{l}\text { Close } \\
\text { Open } \\
\text { Parallel }(\downarrow) \\
\text { Parallel } \\
\text { Open }\end{array}$ & $\begin{array}{l}\text { Fixed thumb } \\
\text { Fixed thumb } \\
\text { Fixed thumb } \\
\text { All(Quick) } \\
\text { All }\end{array}$ \\
\hline $\begin{array}{l}\text { 'swipe' } \\
\text { 'User- } \\
\text { defined' }\end{array}$ & $\begin{array}{l}\text { Dynamic } \\
(\longrightarrow) \\
\text { Dynamic }\end{array}$ & $\begin{array}{l}\text { Parallel } \\
\text { Parallel }\end{array}$ & $\begin{array}{l}\text { All } \\
\text { All }\end{array}$ \\
\hline
\end{tabular}
rejects a gesture.Equal error rate (EER) is an algorithm in biometric security system which is used to determine the
TABLE 4. FEATURES SET [2] [6]

Verification performance of the proposed multi-touch gesture verification system is given by these rates, namely EER, FAR and FRR. Table 4 shows different feature notations. Here for circular movement, CW stands for Clock Wise and CCW stands for Counter Clock Wise.

TABLE 5.EER FOR DTW DISTANCE FUNCTION OF 20 FEATURESSET WITH THREE DIFFERENT COST FUNCTIONS [2]

\begin{tabular}{|l|l|l|l|}
\hline Gesture & Manhattan & Euclidean & Cosines \\
\hline 'CCW' & 5.50 & 4.95 & 8.14 \\
\hline 'CW' & 7.21 & 7.26 & 9.45 \\
\hline 'Pinch' & 8.34 & 9.02 & 9.15 \\
\hline 'Drag' & 9.50 & 9.56 & 8.69 \\
\hline
\end{tabular}




\begin{tabular}{|l|l|l|l|}
\hline 'DDC' & 4.46 & 4.43 & 8.14 \\
\hline 'DUO' & 6.80 & 6.53 & 8.70 \\
\hline 'FDB' & 11.53 & 11.62 & 13.13 \\
\hline 'FBSB' & 6.85 & 7.89 & 6.61 \\
\hline 'FASB' & 9.96 & 9.84 & 11.27 \\
\hline 'FPCCW' & 10.60 & 10.60 & 10.63 \\
\hline 'FPC' & 8.83 & 8.87 & 11.46 \\
\hline 'FPO' & 13.32 & 14.45 & 12.42 \\
\hline 'FPP' & 11.01 & 10.80 & 13.85 \\
\hline 'FTCCW' & 4.48 & 4.54 & 5.33 \\
\hline 'FTCW' & 6.22 & 6.42 & 7.98 \\
\hline 'FTC' & 5.88 & 5.94 & 8.88 \\
\hline 'FTO' & 9.52 & 9.39 & 9.98 \\
\hline 'FTP' & 4.66 & 4.91 & 7.36 \\
\hline 'Flick' & 10.75 & 10.98 & 12.85 \\
\hline 'Opened' & 6.80 & 8.02 & 9.90 \\
\hline 'swipe' & 8.25 & 9.00 & 10.14 \\
\hline $\begin{array}{l}\text { 'User- } \\
\text { defined' }\end{array}$ & 2.98 & 2.85 & 5.86 \\
\hline $\begin{array}{l}\text { Average } \\
\text { EER }\end{array}$ & $\mathbf{7 . 8 8}$ & $\mathbf{8 . 0 9}$ & $\mathbf{9 . 5 4}$ \\
\hline
\end{tabular}

Pixels below the low threshold are classified as background and above the high threshold asobject.

If pixels are adjacent to other object pixels and they are between low and high thresholds then it classified as object[7].

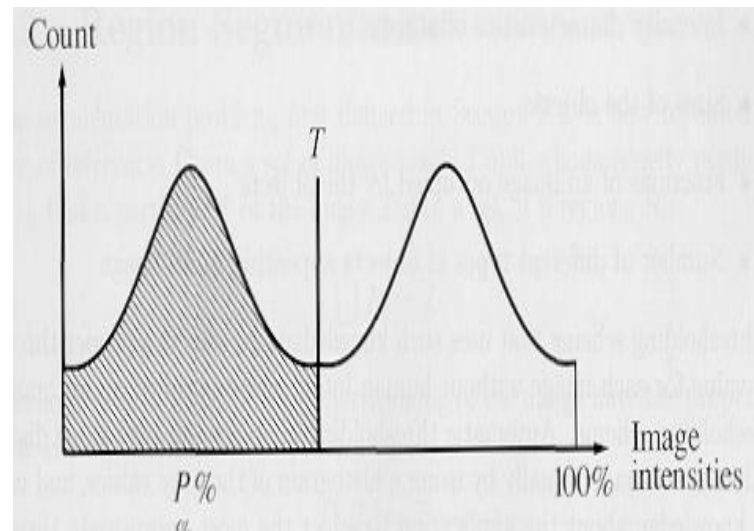

Figure 2. Histogram of thresholding[8]

\section{CONCLUSION}

The results from the algorithm described using three cost In this paper we have studied Gesture Normalization functions are reported in Table 2. Visualization of techniques such as intriguing technique and block scaling. clockwise rotation gesture samples $(\mathrm{CW})$. Specifically, Also we have studied different feature extraction using a single instance of multi-touch gestures, the system techniques, which can be compared based on FAR, FRR achieves verification performance at $7.88 \%$ EER on an and ERR and in that techniques projection based technique average. Author seen that Manhattan distance have have best performance as shown in table no 2.

slightly better performance than Euclidean and the cosine distance. So, Manhattan distance was used as the cost function[2].

\section{THRESHOLDING}

As stated earlier threshold value is selected based on the minimum error criterion and dissimilarities between all the signatures of all the system are computed [1].The simplest approach to segment an image is using thresholding[7].

If $\mathrm{f}(\mathrm{x}, \mathrm{y})>\mathrm{T}$ then $\mathrm{f}$ (x, y) $\square \square 0$ elsef (x, y) $\square \square 255$

A. Automatic thresholding

To make segmentation more robust, In Automatic thresholding the threshold should be automatically selected by the system. To choose the threshold automatically knowledge about the objects, the application, and the environment should be used[7].

B. Choosing the threshold using the image histogram In the histogram regions which have uniform intensity starts to increase to strong peaks. In this casemultilevel thresholding is also possible[7].

\section{Hysteresis thresholding}

Various background pixels which have the same gray level value with object pixels means that histogram of an image have not clear valley.

Also we have studied Distance evaluation techniques such as Manhattan Distance, Euclidean Distance, Cosine Distance and Jaccard Distance out of which Manhattan Distance and Euclidean Distance gives best performance as per the results shown in table no 5 .

In this paper also we have studied Thresholding techniques such as Automatic thresholding, choosing the threshold using image histogram and Hysteresis thresholding.

\section{REFERENCES}

[1] Kalyani Devidas Deshmane, and Prof. S.A. Ghodake, "Android Software based Multi-touch Gestures Recognition for Secure Biometric Modality" 2015 14th International Conference on Information Technology

[2] Napa Sae-Bae, NasirMemon, and Katherine Insisters Computer Science Department, NYU-Poly "Investigating Multi-touch Gestures as a Novel Biometric Modality ".

[3] Automatic Signature Verification: The State of the Art DonatoImpedovo and Giuseppe Pirlo, Member, IEEE transactions on systems, man, and cybernetics - part c: applications and reviews, vol. 38, no. 5, September 2008.

[4] http://www.webopedia.com/TERM/E/equal_error_rate.html.

[5] http://en.wikipedia.org/wiki/Multi-touch.

[6] Napa Sae-Bae, Nasir Memon, and Katherine Isbister Computer Science Department, NYU-Poly "Investigating Multi-touch Gestures as a Novel Biometric Modality ".

[7] Jain et al.," Thresholding" Sections 3.2.1, 3.2.2, Petrou et al., Chapt 7)

[8] Bryan S. Morse," Thresholding" Brigham Young University, 1998200 


\section{BIOGRAPHIES}

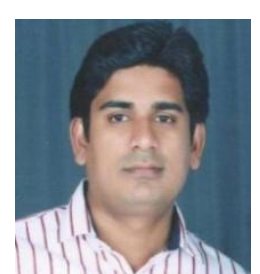

Prof. Ramdas Pandurang Bagawade, Received the B.E. degree in Computer Engineering from Vidya Pratishtans College of Engineering, Baramati in 2008. Also completed M.E. Degree in 2013 from Pune University. Presently he is working in the Department of Computer Engineering at PES's COE Phaltan as an Assistant Professor.

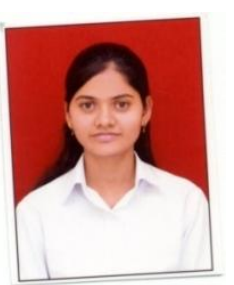

Miss Bhagyashri Satish Bagal Completed diploma at Government Residence Women polytechnic, Tasgaon. Presently she is doing her Bachelor of Engineering from PES's College of engineering, Phaltan

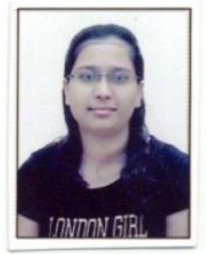

Miss Monika Kishor Kale, Presently she is doing her Bachelor of Engineering from PES's College of engineering, Phaltan

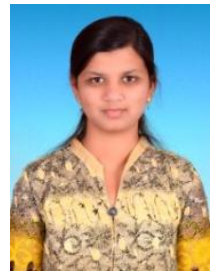

Miss Trupti Chandrakant Jangam, Presently she is doing her Bachelor of Engineering from PES's College of engineering, Phaltan 